\title{
Study of Organic Radicals Generated upon Naphthoquinone-Hydantoins Reactions in Basic Aqueous Solution ${ }^{+}$
}

\author{
Enrique Flores 1, Ernesto Rivera-Avalos ${ }^{1}$, Braulio Rodríguez-Molina 2, Carlos Frontana ${ }^{3}$, \\ Lluvia López ${ }^{4, *}$ and Denisse de Loera ${ }^{1, *}$
}

Citation: Flores, E.; Rivera-Avalos, E.; Rodríguez-Molina, B.; Frontana, C.; López, L.; de Loera, D. Study of Organic Radicals Generated upon Naphthoquinone-Hydantoins Reactions in Basic Aqueous Solution. Chem. Proc. 2021, 3, 58 https://doi.org/10.3390/ecsoc-2408415

Academic Editors: Julio A. Seijas and M. Pilar Vázquez-Tato

Published: 14 November 2020

Publisher's Note: MDPI stays neutral with regard to jurisdictional claims in published maps and institutional affiliations.

Copyright: $₫ 2020$ by the authors. Licensee MDPI, Basel, Switzerland. This article is an open access article distributed under the terms and conditions of the Creative Commons Attribution (CC BY) license (http://creativecommons.org/licenses/by/4.0/).
1 Facultad de Ciencias Químicas, Universidad Autónoma de San Luis Potosí, Av. Dr. Manuel Nava No. 6, Zona Universitaria, 78210 San Luis Potosí, Mexico; eflopez21@hotmail.com (E.F.); neto_riava@hotmail.com (E.R.-A.)

2 Instituto de Química, Universidad Nacional Autónoma de México, Circuito Exterior s/n, Ciudad Universitaria, Alcaldía Coyoacán, 04510 Cd. de México, Mexico; brodriguez@iquimica.unam.mx

3 Parque Tecnológico Querétaro, s/n, Sanfandila, 76703 Pedro Escobedo, Mexico; cfrontana@cideteq.mx

4 Instituto de Investigación de Zonas Desérticas, Universidad Autónoma de San Luis Potosí, De Altair No. 200, Col del Llano, 78377 San Luis Potosí, Mexico

* Correspondence: lluvia.lopez@uaslp.mx (L.L.); atenea.deloera@uaslp.mx (D.d.L.); Tel.: +52-444-842-2359 (L.L.); +52-444-826-2300x6415 (D.d.L.)

+ Presented at the 24th International Electronic Conference on Synthetic Organic Chemistry, 15 November-15 December 2020; Available online: https:/ecsoc-24.sciforum.net/.

\begin{abstract}
In this work, the synthesis of thiohydantoins from L-amino acids and isothiocyanates was studied, using a high purity method based on the Edman cycle. This process, expected to occur through the Michael addition to a series of 1,4-naphthoquinone derivatives did not lead to the expected final product, rather leading to a colored mixture of compounds, where EPR spectra showed that some of them presented unpaired electrons, indicating that an electron transfer pathway was also involved in the reaction mixture. Detected organic radicals proved to be stable albeit with the use of different experimental conditions. Voltammetric results indicated that the reactions led to the formation of electroactive species, probably derived by homogeneous electron transfer between the reactive quinone moieties and the oxidizable urea functions within the hydantoin species.
\end{abstract}

Keywords: radicals; naphthoquinones; hydantoins; EPR

\section{Introduction}

Hydantoins (Figure 1) are a group of five membered heterocycles containing a reactive urea core (or an analog) which present multiple biological activities including antiviral, antiarrhythmic and antiandrogenic properties as well as being present in compounds used as fungicides, herbicides and pesticides [1-3]. These properties have made hydantoins an important element in fragment-based pharmaceutics design [4].

Quinones can be chemically or electrochemically reduced to form hydroquinones, involving the formation of radical anion $\left(\mathrm{Q}^{-}\right)$and dianion species $\left(\mathrm{Q}^{2-}\right.$, Figure 2$)$, which interact with polar biological elements like proteins, DNA and oxygen $[5,6]$. 
<smiles>O=C1CNC(=O)N1</smiles>

Figure 1. Hydantoin general structure.<smiles>CCCCC1=CC(=O)C=CC1=O</smiles>

(a)<smiles>O=C1C=CC(=O)C=C1</smiles>

(b)<smiles>C=Cc1cc([O-])ccc1O</smiles>

(c)<smiles>C=Cc1cc(O)ccc1O</smiles>

(d)

Figure 2. Quinone/hydroquinone redox mechanism: (a) quinone; (b) anion radical; (c) dianion species; (d) hydroquinone.

On the other hand, quinone compounds are well-known electrophilic compounds, enhanced by the electronic characteristics of the substituents and thus they are convenient Michael acceptors for 1,4 additions. In Michael addition processes, a nucleophilic addition to a $\beta$ carbon of an $\alpha, \beta$-unsaturated carbonyl in the naphthoquinones can be done with substituted hydantoins as an electrophile. Acyclic amine additions to naphthoquinones are reported in the literature, where heptahydrate cerium trichloride is used as a catalyst to add anilines to 5-hydroxy-1,4-naphthoquinones [7], and in more recent reports, the addition of different amino acids to 1,4-naphthoquinone using triethylamine and potassium hydroxide in dioxane water by microwave irradiation has been described [8].

Interestingly, in the above mentioned reports, the formation of radical species was reported, which could be explained when considering hydantoin moieties as an electron source and thus oxidizable species. To obtain more information on this aspect of the reaction, further structure elucidation of the final products, including cyclic voltammetry analysis and electron spin resonance (ESR) [9] was used and the structure proposals of the obtained compounds are presented.

\section{Methods}

\subsection{Thiohydantoins Synthesis}

Thiohydantoins were synthetized using the Edman Cycle variation from Seung-Ju Yang et al. [10] with some modifications: A solution of isocyanate (phenylisocyanate, ethylisocianate) in 1,4-dioxane:water $1: 1$ mixture at $0{ }^{\circ} \mathrm{C}$ was added to a proper L-Amino acid (1 eq.) and stirred for $15 \mathrm{~min}$. Triethylamine (2 eq.) was added slowly to the solution and stirring continued for $1 \mathrm{~h}$, followed by the slow addition of concentrated $\mathrm{HCl}$ until the $\mathrm{pH}$ was approximately 2 ; in these conditions, the reaction continued for up to 4 days. A saturated solution of $\mathrm{NaHCO}_{3}$ was used to adjust the solution $\mathrm{pH}=6$ and the formed precipitate was filtered and washed with a 1:1 1,4-dioxane:water mixture.

\subsection{Naphthoquinone-Hydantoins Hybrids Synthesis}

Commercially available 1,4-naphthoquinone, 2,3-dichloronaphthoquinone, hydantoin and thiohydantoin were used for the synthesis. A solution of 1 equivalent of hydantoin or thiohydantoin was prepared in 1:1 1,4-dioxane:water mixture in the presence of an alkali salt; the solution was introduced into the microwave oven and heated at $100{ }^{\circ} \mathrm{C}, 400$ $\mathrm{W}$ for $5 \mathrm{~min}$ to deprotonate the acidic $\mathrm{NH}$ function. Afterwards, heating was stopped and 1 equivalent of either 1,4-naphthoquinone or 2,3-dichloronaphthoquinone was added to 
the solution and the reaction continued by the same conditions for $20 \mathrm{~min}$. Products were purified by column chromatography. An scheme of the process is shown in Figure 3.<smiles>[R]NC(=S)NC([R2])C(=O)O</smiles>

$$
\begin{aligned}
& \text { 1a, } R_{1}=\text { Phenyl } \\
& 2 \text { 2c, } \mathrm{R}_{2}=\mathrm{H} \\
& 3 \\
& \text { 1b, } \mathrm{R}_{1}=\text { Ethyl }
\end{aligned}
$$

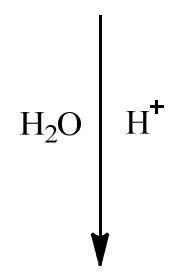

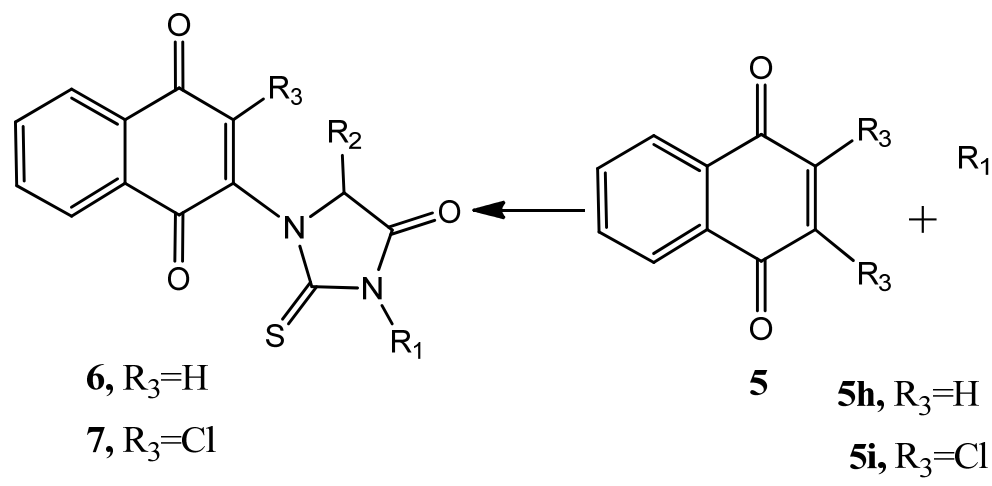

Figure 3. General scheme of the employed synthetic procedure.

\subsection{Product Characterization}

${ }^{1} \mathrm{H}$ and ${ }^{13} \mathrm{C}$ nuclear magnetic resonance (NMR) spectra were recorded on a Bruker Avance III $400 \mathrm{MHz}$ spectrometer. High-resolution mass spectra (HRMS) were measured with a Jeol JMS-AccuTOF through DART (direct analysis in real time). Infrared spectra were recorded on a Thermo Scientific NICOLET iS10 with ATR dispositive. Electron spin resonance (ESR) spectra were recorded on a Jeol JES-TE300 spectrometer. Melting points were determined using a Bicote-Stuart SMO 10 apparatus.

Cyclic voltammograms were obtained using a three electrode set-up, using a glassy carbon disk $(\phi=3 \mathrm{~mm})$ as working electrode, a platinum wire as counter electrode and a $\mathrm{Ag} \mid \mathrm{AgCl} 0.1 \mathrm{M}$ in $\mathrm{CH}_{3} \mathrm{CN}$ was employed as reference electrode. Electrode potential values are referred to the $\mathrm{Fc} / \mathrm{Fc}^{+}$couple as recommended by IUPAC. An AUTOLAB PGSTAT $302 \mathrm{~N}$ potentiostat/galvanostat was employed for recording the electrochemical responses.

\section{Results and Discussion}

\subsection{Thiohydantoin Synthesis}

Thiohydantoins were synthetized with relatively good yields; even though the reaction takes a long time to proceed (more than $24 \mathrm{~h}$ ), no further purification was needed (Table 1). All molecules were completely characterized by NMR, HRMS, IR and melting point determinations. 
Table 1. Yields obtained in thiohydantoin synthesis.

\begin{tabular}{cc}
\hline Compound $^{1}$ & Yield (\%) \\
\hline 4ac & 65 \\
4ad & 73 \\
4ae & 62 \\
4af & 69 \\
4ag & 58 \\
4bd & 55 \\
4be & 56 \\
4bf & 52 \\
\hline
\end{tabular}

${ }^{1}$ First letter: isothiocyanate substituent, second letter: amino acid substituent.

\subsection{Naphthoquinone-Hydantoins Hybrids Synthesis}

Thiohydantoin deprotonation with $\mathrm{DABCO}$ and $\mathrm{Cs}_{2} \mathrm{CO}_{3}$ showed a color change from yellow (neutral) to pink ( $\mathrm{pH}>8$ ), and then 2,3-dichloronaphthoquinone was added to the solution and the mixture were irradiated.

A pink/purple product formed for all the thiohydantoins, this product was extracted in DCM and purified by flash column chromatography (DCM:MeOH 9:1). NMR spectra were obtained for all the products but the proper assignment of the signals could not be performed even though different solvents were employed. As described above, it is widely known that hydantoins and quinones generate radicals as reaction intermediates, which would explain the difficulty in obtaining good NMR spectra as the presence of a radical in the molecule overlaps due to the higher electron magnetic moment over the nuclear magnetic moment that can be up to $10^{3}$ times larger [11]. Therefore, as an alternative, electron spin resonance of the products was obtained. In these spectra, characteristic paramagnetic organic radicals were detected (Figure 4), however, the low amount of these species did not lead to proper resolution of the spectra.

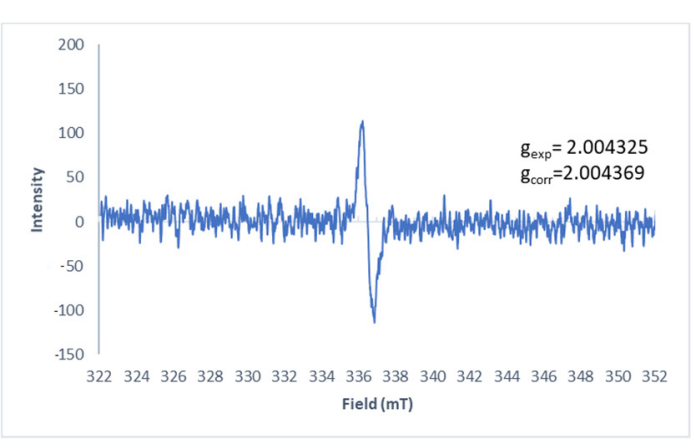

(a)

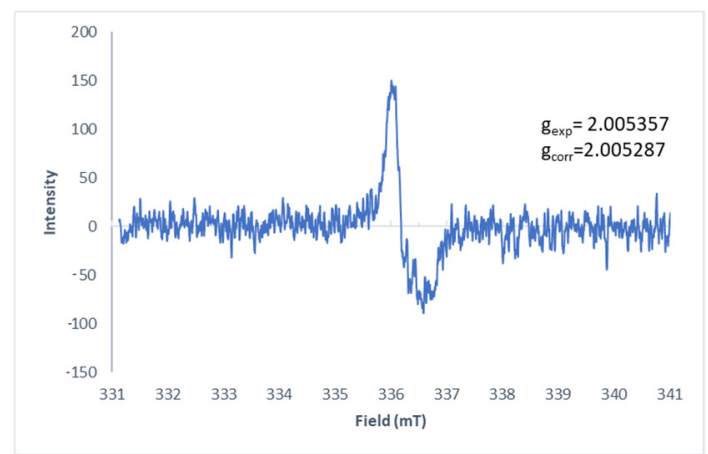

(b)

Figure 4. Solid state EPR spectra of (a) 7ad and (b) 7ac.

Experiments with commercial thiohydantoin led us to obtain a well-defined spectrum in methanol (Figure 5). A quintuple with 1:2:3:2:1 relative intensity peaks was observed, this could be consistent with the presence of 2 nitrogen atoms within the structure, both with spin number of 1 , according to $2 n i+1$ formula for multiplicity or equivalent hydrogens from the aromatic ring, studies are now in progress to determine the possible structure. 


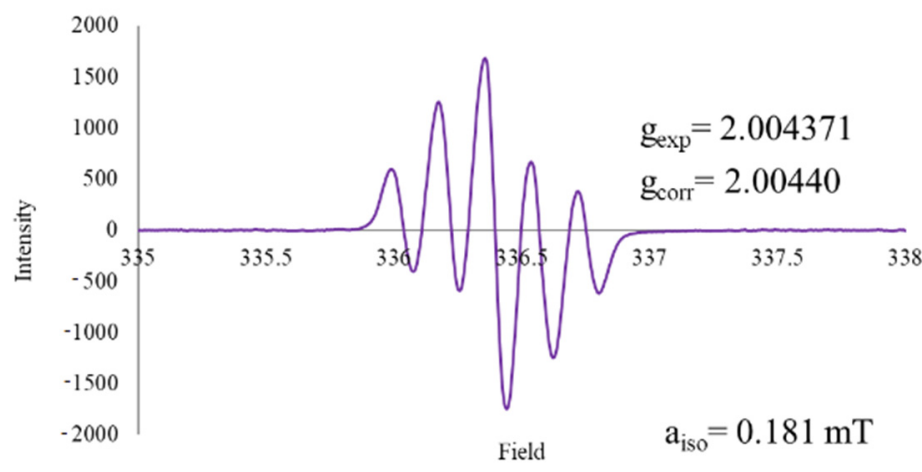

Figure 5. EPR spectrum for thiohydantoin-naphthoquinone hybrid.

Unsubstituted thiohydantoin possesses 3 acidic hydrogens that can be subtracted to achieve the addition, so 3 possible products, including recombination, were expected. According to the quintuple obtained from the EPR spectra, a possible structure is one with the stabilization of the radical between the 2 nitrogen atoms, Figure 6 .<smiles>O=C1C=C(C2NC(=S)NC2=O)C(=O)c2ccccc21</smiles>

Figure 6. Proposed chemical structure for thiohydantoin-naphthoquinone hybrid.

Different synthetic pathways were explored to generate the thiohydantoine cycle over the naphthoquinone core by performing first the addition of amino acids to the naphthoquinones, followed by cyclization with isothiocyanates but this procedure lead to the same result. HRMS were also performed, small ion mass variations in the products were found. Product 6ad had ion masses of 379.07404 and $391.2826 \mathrm{~m} / z$ (Figure 7), compared to the expected mass of $397.034 \mathrm{~m} / \mathrm{z}$ (Figure 8a).

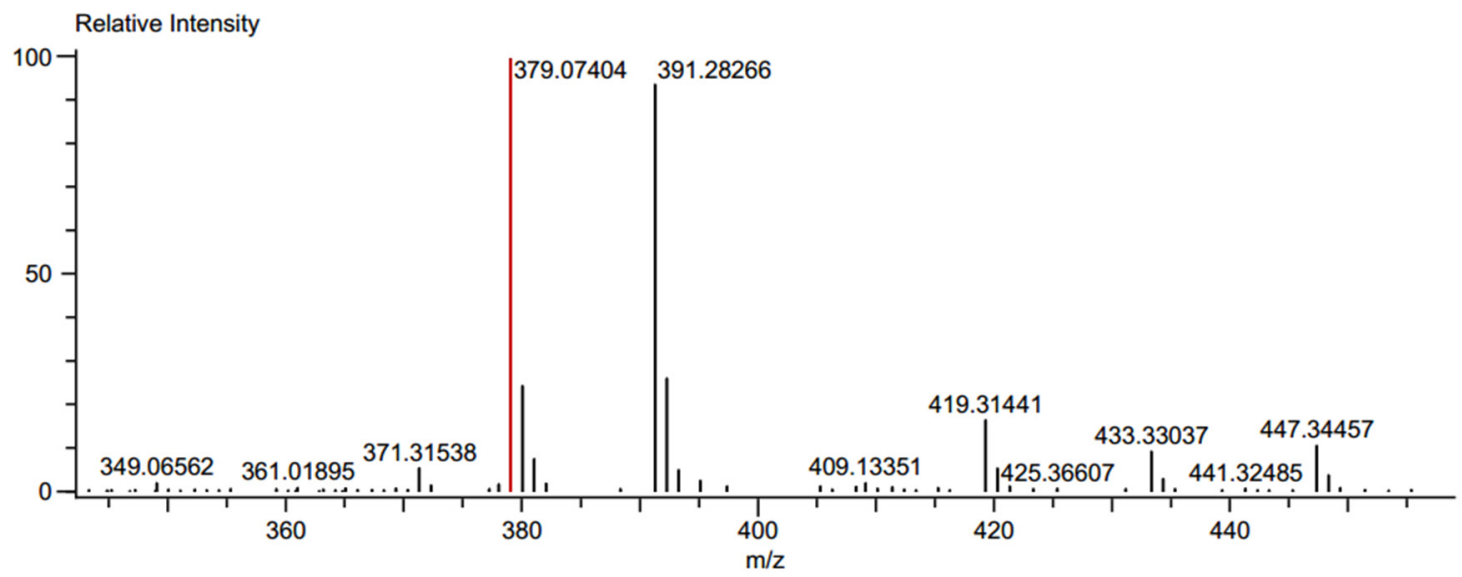

\begin{tabular}{|c|c|c|c|c|c|}
\hline Mass & Intensity & Calc. Mass & $\begin{array}{l}\text { Mass Difference } \\
(\mathrm{mmu})\end{array}$ & $\begin{array}{l}\text { Mass Difference } \\
(\mathrm{ppm})\end{array}$ & Possible Formula \\
\hline 379.07404 & 645817.83 & 379.07525 & -1.21 & -3.2 & $715 \cdot 72-04-31$ \\
\hline
\end{tabular}

Figure 7. HRMS spectrum of product 6ad. 
Figure 8. Chemical structure for 6ad: (a) expected; (b) proposed.

According to literature, thiohydantoins exposed to alkaline solutions are easily ionized and in continuous exposition, the cycle tends to open [12]. Therefore, it is possible that thiohydantoin could be added and later the cycle would tend to open via the N-CO bond, cyclying again by both nitrogen atoms forming the proposed chemical structure shown in Figure 8b. The same authors expressed that substituted thiohydantoins in C5 and N3 would lead to a N1 atom remaining free, stabilizing their ionization between the free nitrogen and thiocarbonyl carbon [13], thus reinforcing the results obtained from the EPR spectra.

Cyclic voltammetry (CV) preliminary studies for obtained products showed the presence of anodic/cathodic reversible peaks corresponding to naphthoquinone reductions (Peaks IIc and IIIc in Figure 9) and the possible cathodic peak from thiohydantoin (Peak Ia in Figure 9b).

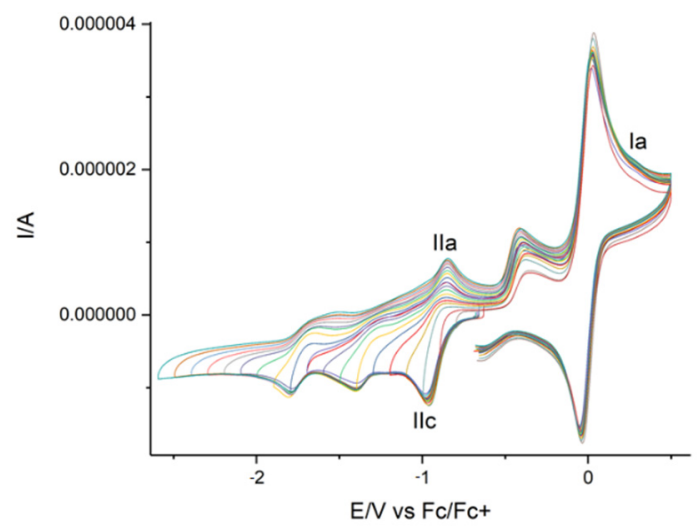

(a)

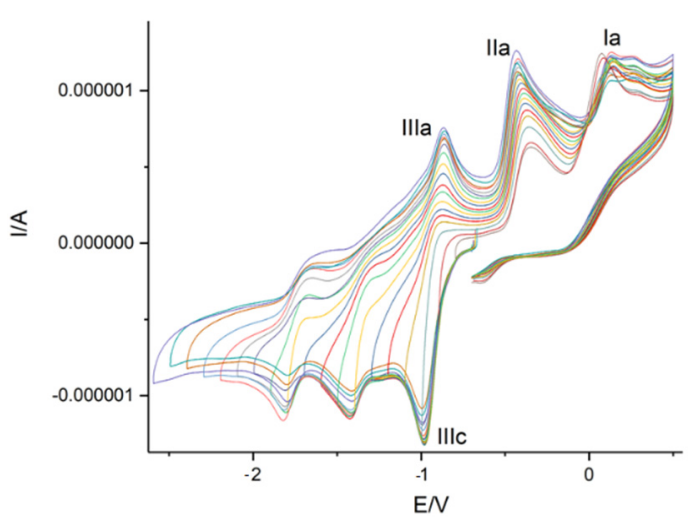

(b)

Figure 9. Cyclic voltamperogram for thiohydantoin-naphthoquinone hybrid: (a) with ferrocene, (b) without ferrocene.

Michael additions of the thiohydantoins were done over $\alpha, \beta$-unsaturated carbonyl systems different from quinones under the same conditions and the expected products were formed and identified by NMR. Further studies of these compounds are already in process to obtain better information that will allow us to correctly explain the chemical nature of these interesting products. 


\section{Conclusions}

Hydantoins ionization are potentiated by redox properties of naphthoquinones to form hydantoin-naphthoquinone hybrids that represent an interesting family of radical persistent compounds with as yet uncertain chemical structure. Reaction conditions are useful for hydantoin additions to $\alpha, \beta$-unsaturated carbonyl compound lacking redox properties, this also represents an opportunity to keep exploring the reactivity of hydantoin derivatives in different conditions. Future work is required in the matter of ESR and $\mathrm{CV}$ to obtain the proper parameters for the radical structure elucidation, and it is in progress.

Funding: This research was funded by the National Council for Science and Technology, Grant number CB-2013-01-220844 and PhD Scholarship number 304251.

Institutional Review Board Statement: Not applicable.

Informed Consent Statement: Not applicable.

Data Availability Statement: The data presented in this study are available on request from the corresponding author. The data are not publicly available due to studies in progress.

Acknowledgments: Acknowledge to the Braulio's team from Instituto de Química of the UNAM, and Carlos's team from CIDETEQ, and technical support to Q. María de los Ángeles Peña González, M.C. Elizabeth Huerta Salazar, Dra. María del Carmen García González, M. C. Virginia Gómez Vidales and Q.F.B. María del Rocío Patiño Maya.

Conflicts of Interest: The authors declare no conflict of interest.

\section{References}

1. Safari, J.; Javaian, L. Montmorillonite K-10 as a catalyst in the synthesis of 5, 5-disubstituted hydantoins under ultrasound irradiation. J. Chem. Sci. 2013, 125, 981-987.

2. Majumdar, P.; Bathula, C.; Basu, S.M.; Das, S.K.; Agarwal, R.; Hati, S.; Singh, A.; Sen, S.; Das, B.B. Design, synthesis and evaluation of thiohydantoin derivatives as potent topoisomerase I (Top1) inhibitors with anticancer activity. Eur. J. Med. Chem. 2015, $102,540-551$.

3. Evdokimova, N.M.; Magedovb, I.V.; McBrayerb, D.; Kornienko, A. Isatin derivatives with activity against apoptosis-resistant cancer cells. Bioorg. Med. Chem. Lett. 2015, 26, 1558-1560.

4. Caturelli, J.; Martini, M.F.; Fabian, L.; Moltrasio, G.Y.; Moglioni, A.G. Synthesis and spectroscopic characterization of cyclobutyl hydantoins. J. Mol. Struct. 2018, 1171, 495-502.

5. Leyva, E.; López, L.I.; Loredo-Carrillo, S.E.; Rodríguez-Kessler, M.; Montes-Rojas, A. Synthesis, spectral and electrochemical characterization of novel 2-(fluoroanilino)-1,4-naphthoquinones. J. Fluor. Chem. 2011, 132, 94-101.

6. Su, C.; Liu, Z.; Wang, Y.; Wang, Y.; Song, E.; Song, Y. The electrophilic character of quinones is essential for the suppression of. Toxicology 2017, 387, 17-26.

7. Lopez-Lopez, L.I.; Garcia, J.J.V.; Saenz-Galindo, A.; Silva-Belmares, S.Y. Ultrasonic and Microwave Assisted Synthesis of Nitrogen-Containing Derivatives of Juglone as Potential Antibacterial Agents. Lett. Org. Chem. 2014, 11, 573-582.

8. Rivera-Avalos, E.; de Loera, D.; Araujo-Huitrado, J.G.; Escalante-García, I.L.; Muñoz-Sánchez, M.A.; Hernández, H.; López, J.A.; López, L. Synthesis of Amino Acid-Naphthoquinones and In Vitro Studies on Cervical and Breast Cell Lines. Molecules 2019, 24,4285 .

9. Duin, E. Electron Paramagnetic Resonance Theory; Available online: http://webhome.auburn.edu/ duinedu/epr/1_theory.pdf (accessed on 10 November 2020).

10. Yang, S.J.; Lee, J.M.; Lee, G.H.; Kim, N.Y.; Kim, Y.S.; Gong, Y.D. Microwave assisted synthesis of 1,3,4-oxadiazole/thiohydantoin hybrid derivatives via dehydrative cycliztion of semicarbazide. Bull. Korean Chem. Soc. 2014, 35, 3609-3617.

11. Elguero, M.D.; Alkorta, J.; Pardo, I.; Claramunto, C.; María, R.M.S. Resonancia Magnética Nuclear de Protón: Aplicaciones en Química Orgánica. Available online: http://www.are.iqm.csic.es/cursos/rmn_parte1.pdf (accessed on 10 November 2020).

12. Edward, J.; Nielsen, S. Thiohydantoins. Part II Alkaline Hydrolyses. J. Chem. Soc. (Resumed) 1955, 5080-5083.

13. Edward, J.; Nielsen, S. Thiohydantoins. Part I. Ionisation and Ultraviolet Absorption. J. Chem. Soc. (Resumed) 1957, 5075-5079. 